\title{
Estudo Sobre a Constituição de um Sistema Social em Ambiente Virtual de Aprendizagem
}

\section{A Study About the Constituition of the Social System in Virtual Learning Environment}

\begin{abstract}
Resumo: Este artigo propõe uma visão de comunidade em ambiente virtual de aprendizagem específico, observando seu processo de constituição. Tendo como referência a teoria da Biologia do Conhecer, de Humberto Maturana, foi estudada a rede conversacional que se constituiu na instância do "correio", ferramenta de comunicação em um Curso de Especialização semipresencial. Buscou-se identificar o acoplamento estrutural entre os participantes do curso no espaço coordenação/tutoria e o ambiente virtual de aprendizagem e, a partir deste acoplamento, a constituição de um sistema social. Para tal, foram mapeadas as mensagens produzidas por meio da ferramenta "correio", do ambiente, através de categorias, o que permitiu identificar tanto o acoplamento dos participantes do curso com o ambiente como a constituição do próprio sistema social, enquanto uma comunidade de aprendizagem.

Palavras-chave: Ambiente Virtual de Ensino Aprendizagem. Redes de Conversação. Sistema Social.
\end{abstract}

Abstract: This theory proposes the vision of community of learning in virtual environment of specific learning, observing its process of the formation. Taking as reference the theory of the Biology Knowing of Humberto Maturana, it was studied the network conservation that constituted itself in the instance of "email", tool of communication in a Specialization Course. It was tried to identify the structural coupling between the participants of the course in the space coordination/mentoring and the virtual environment of learning and from this coupling the establishment of a social system. So, it was mapped the massages produced from the tool "emails", of the environment, through the category, allowing to identify both the coupling of the participants of course with environments as the creation of the own social system, while a community of learning.

Keywords: Virtual Environment for Teaching and Learning. Conversation Networks. Social System.

ROCHA, Karla Marques da; AXT, Margarete. Estudo sobre a constituição de um sistema social em ambiente virtual de aprendizagem. Informática na Educação: teoria e prática, Porto Alegre, v. 17, n. 1, p. 183-199, jan./jun. 2014.

\author{
Karla Marques da Rocha \\ Universidade Federal de Santa Maria \\ Margarete Axt \\ Universidade Federal do Rio Grande do Sul
}

\section{Introdução}

U timamente, mais especificamente das últimas duas décadas do século XX para cá, estamos vivendo em um mundo de constantes mudanças, tanto no campo social, econômico e político quanto no da cultura, da ciência e, principalmente no campo da tecnologia, que vem revolucionando as formas de comunicação e de relacionamento entre as pessoas. Algumas mudanças se configuram devido ao desenvolvimento tecnológico, principalmente ao que se refere às Tecnologias da Informação e Comunicação (TIC).

Novas formas de produção e distribuição do conhecimento alteram a organização, o planejamento dos conteúdos - através dos diferentes meios de comunicação -, a relação entre o aluno e o professor e os alunos entre si e a 
adaptação do professor e do aluno com a tecnologia e com os novos espaços.

Surgem assim, novos espaços de interação, e a educação, acompanhando as mudanças e evoluções tecnológicas, deve usar a tecnologia para proporcionar, nesse sentido, um enriquecimento dos ambientes de aprendizagem, oportunizando, assim, "espaços de convivência".

Esse "espaço de convivência" pode oferecer aos professores e alunos uma possibilidade de alterar seus modos de interagir e conversar na busca de novos domínios conversacionais e de aprendizagem, acoplados à tecnologia. Com isso, os Ambientes Virtuais de Ensino e Aprendizagem (AVEA) mediados pelas tecnologias, podem oferecer a seus participantes a possibilidade de constituir redes de conversação, trocando, com isso, informações, estabelecendo relações sociais, que produzem e compartiIham conhecimento.

Os AVEA podem ser entendidos como uma comunidade relacional organizada, que reúne e interliga atores e informações, otimizando os recursos individuais, potencializando a capacidade de atuação de cada um. Chamamos de atores as pessoas que se comunicam e se relacionam. A interação das partes fortalece 0 andamento do grupo. A ligação desses atores, dentro de um determinado espaço virtual, precisa ser construída por meio da convivência, onde todos possam transformar-se de maneira congruente. Transformamo-nos ao conviver com os outros e essa transformação ocorre enquanto o organismo estiver em acoplamento com o meio (MATURANA, 2001). Esse espaço de convivência, quando vinculado a um curso a distância, pode ser denominado de "ambiente de aprendizagem" ou, quem sabe, "comunidade Virtual de Aprendizagem".

Shaffer e Anundsen (apud PALLOF e PRATT,
2002, p.50), definem comunidade como um todo dinâmico, que emerge quando um grupo de pessoas compartilha determinadas práticas, é interdependente, toma decisões em conjunto, identifica-se com algo maior do que o somatório de duas relações individuais e estabelece um compromisso de longo prazo com o bem-estar (o seu, o dos outros e o do grupo, em todas as suas inter-relações). Portanto, uma comunidade é uma estrutura social estabelecida de forma orgânica, ou seja, se constitui a partir de dinâmicas coletivas e historicamente únicas. Sua própria história e sua cultura definem uma identidade comunitária. Seu reconhecimento deve ser coletivo e será fundamental para os sentidos de pertencimento dos seus cidadãos e desenvolvimento comunitário.

Pelo fato de uma comunidade virtual de aprendizagem referir-se, geralmente, a um conjunto de pessoas (coordenadores, tutores e monitores), de tecnologias, constituídos sob a emoção do compromisso com o curso, onde existe a aceitação de um acordo na realização de uma tarefa, este pode constituir-se em um sistema social.

Um sistema social pode formar-se a partir do momento em que um grupo pertencente, por exemplo, a um espaço coordenação/tutoria, acoplado ao ambiente virtual e sob a emoção, que constitui o espaço de ações de aceitação do outro na convivência, gera uma rede de interações que produz um espaço no qual seus participantes podem se realizar a si próprios.

Esta rede de interações se estabelece, então, nas coordenações consensuais de ações que envolvem não a paridade de conceitos dos envolvidos na ação da fala, mas a construção de compreensões em torno de um fenômeno comum que vai sendo interpretado de acordo com a própria história construída em torno dos conceitos e da história estrutural do sistema 
interpretante. Portanto, as redes de conversação podem ser consideradas como um espaço de ações que se tornam comuns, ou seja, um espaço de ações que, por lidarem com elementos comuns da linguagem, se tornam consensuais.

O presente artigo, sendo parte de uma tese de doutorado, objetiva relatar a ocorrência de acoplamentos entre os participantes de um Curso de Especialização em Humanização da Atenção e Gestão do SUS (Sistema Único de Saúde), no espaço coordenação/tutoria e cujo efeito nuclear seja a constituição de um Sistema Social.

Propomos uma visão de comunidade em ambiente virtual de aprendizagem específico, observando seu processo de constituição. Tendo como referência a teoria da Biologia do Conhecer, de Humberto Maturana, estuda-se a rede conversacional que se constitui na instância do "correio", ferramenta de comunicação em um Curso de Especialização.

Neste contexto surgem três etapas: análise das redes de conversação que se estabeleceram a partir da ferramenta "correio" do ambiente virtual de aprendizagem TelEduc; verificação do acoplamento estabelecido entre os participantes do curso no espaço da coordenação/tutoria e o ambiente virtual de aprendizagem; Observação do processo de constituição de um sistema social a partir do acoplamento entre os participantes do Curso no espaço coordenação/tutoria e ambiente virtual de aprendizagem.

\section{Redes de conversação específicas e os acoplamentos possíveis}

A partir do Curso de Pós-graduação Lato Sensu em nível de Especialização em Humani- zação da Atenção e Gestão do SUS, desenvolvido na modalidade semipresencial, realizado no Rio Grande do Sul - UFRGS - em 2007, numa parceria de cooperação técnica entre o Ministério da Saúde, UFRGS (universidade Federal do Rio Grande do Sul), UNIJUÍ (Universidade Regional do Noroeste do Estado do rio grande do Sul) e UFF (Universidade Federal Fluminense) foi possível observar e analisar a rede de conversação estabelecida na instância da ferramenta Correio do ambiente de aprendizagem TelEduc.

O curso contou com uma comissão coordenadora (representada pelas universidades parceiras), com oito tutoras de diferentes municípios do Rio Grande do Sul, duas monitoras, duas bolsistas e setenta e três alunos. No chamado espaço coordenação/tutoria (curso no TelEduc) as tutoras, junto com a comissão coordenadora, aprenderam, como alunas, a serem formadoras para assim, poderem atuar junto a seus alunos - alunos do Curso de especialização, nos seus respectivos espaços de tutoria. Portanto, o espaço coordenação/tutoria foi um ambiente destinado à interação do grupo, ao esclarecimento de dúvidas, ao debate e às soluções de problemas. Este ambiente foi o espaço onde a pesquisa se desenvolveu, acompanhando os processos de acoplamento do pequeno conjunto de participantes com o ambiente virtual.

Se tomarmos como base as idéias de Maturana e Varela (1997a, 2001), ao observarem um sistema vivo e o meio em que ele vive, podemos perceber que tanto o sistema como o meio podem se modificar de forma congruente. Como exemplo, podemos observar um grupo de alunos que está sempre se ajustando ao ambiente e vice-versa. De igual modo, num ambiente virtual - AV - um acoplamento entre professores, alunos e ambiente poderá produ- 
zir, simultaneamente, um grupo de aprendizagem (na forma de um sistema social) e um ambiente de aprendizagem (na forma de um AVA - ambiente virtual de aprendizagem (AXT, 2004). É uma boa maneira de dizer que o meio produz mudanças na estrutura dos sistemas, que por sua vez agem sobre ele, alterando-o, numa relação circular. A esse fenômeno Maturana e Varela (1997a, 2001) deram o nome de "acoplamento estrutural". De igual maneira, um organismo influencia outro, este replica influindo sobre o primeiro. Ou seja, desenvolve uma conduta compensatória. O primeiro organismo, por sua vez, dá a réplica, voltando a influenciar o segundo, que por seu turno retruca - e assim por diante, enquanto os dois continuarem em acoplamento (MARIOTTI, 2005).

Neste contexto, a partir da observação da ferramenta assíncrona Correio do ambiente TelEduc no espaço coordenação/tutoria, foram salvas e analisadas 708 mensagens, correspondentes a nossos sujeitos, no período de 20 de abril de 2007 a 11 de abril de 2008. A escolha do "correio" deve-se ao fato de ter sido a ferramenta mais utilizada pelos participantes do espaço coordenação/tutoria e segundo as próprias tutoras, foi a ferramenta com mais facilidade de acesso. As conversas analisadas, abordavam assuntos relacionados com a tecnologia, seus grupos de alunos, temas pessoais e específicos da PNH (Política Nacional de Humanização), as intervenções das tutoras como gestoras em suas unidades de saúde.

Para fins de complementaridade do trabalho utilizou-se, também, um questionário contendo nove perguntas abertas aplicado às tutoras.
O mesmo visou coletar dados sobre as tutoras, suas experiências com educação a distância, especialmente detalhes sentidos e percebidos por elas sobre os processos de acoplamento com o ambiente TelEduc e as relações entre si.

Para melhor organização e compartilhamento das informações o Curso foi estruturado em dez espaços (10 "cursos" no TelEduc).

1. Espaço da coordenação/tutorias: espaço primeiro onde se reuniu a comissão coordenadora (06), as tutoras (08) e monitoras (02), sem alunos. Ambiente destinado à interação do grupo, ao esclarecimento de dúvidas, ao debate e às soluções de problemas.

2. Espaço do curso de especialização: espaço segundo onde foram publicados todos os materiais do curso e orientações gerais. Ambiente onde os alunos aprenderam a usar o TelEduc. Neste espaço, todos os participantes (coordenação, tutoras, monitoras e alunos) estavam cadastrados com login/senha.

3. Espaço de tutoria: um espaço terceiro para cada tutora e seu grupo de apoiadores (alunos). A coordenação pedagógica, a tutora do grupo e as monitoras podiam acessar este espaço além dos alunos respectivos. Como eram oito tutoras distribuídas pelo Rio Grande do sul, foram oito espaços de tutoria. Cada tutora com oito alunos, sendo que em alguns grupos o número excedeu. Então as tutoras tinham que acessar Três diferentes espaços no TelEduc. A Figura 01 procura ilustrar os dez espaços contemplados pelo curso e suas interações. 


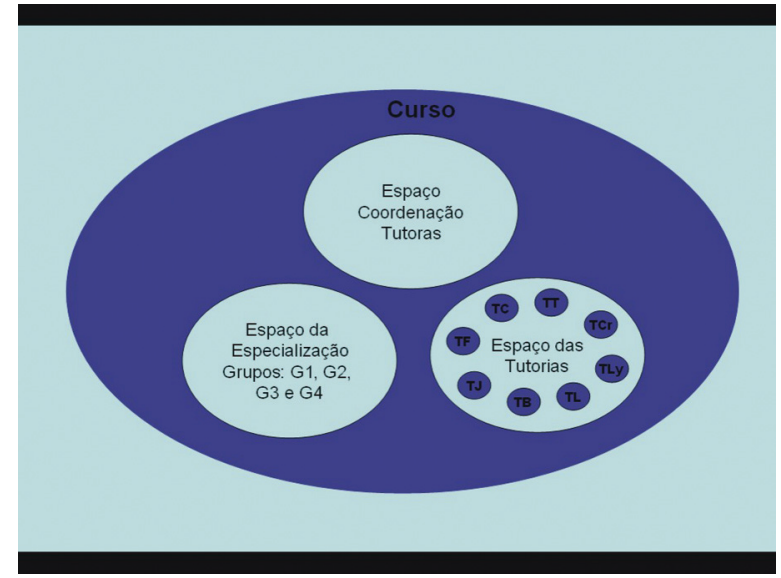

Figura 1. Espaços contemplados pelo curso

O espaço selecionado para coletar os dados da pesquisa foi o espaço primeiro, da Coordenação/tutoria do Curso de Especialização em Humanização da Atenção e Gestão do SUS, em que o objetivo foi analisar as redes de conversação, através do conjunto de mensagens obtido no âmbito da ferramenta "correio", do ambiente TelEduc.

\section{Metodologia de análise}

Considera-se que os "espaços de convivência", no caso o ambiente virtual de aprendizagem, oferecem aos coordenadores, tutores e monitores uma possibilidade de alterar seus modos de interagir e conversar na busca de novos domínios conversacionais e de aprendizagem. Neste acoplamento entre ambiente virtual de aprendizagem e os participantes do curso, no espaço coordenação/tutoria, sustentados pela emoção e pela aceitação do outro na convivência, o entrelaçar de condutas produz, em nosso entender, um espaço no qual seus participantes se realizam, constituindo um sistema social. Com este pressuposto, e tendo como foco a questão de pesquisa e os objetivos já expostos, identificamos três focos de conversas (três categorias específicas) a partir das 708 mensagens analisadas na coleta de dados da ferramenta correio do ambiente TelEduc no período de 20 de abril de 2007 a 11 de abril de 2008.

Estes três focos de conversas nos chamaram mais a atenção, não só pela intensidade e tempo de duração das conversas, mas especialmente pelo envolvimento dos sujeitos participantes. O primeiro grupo (foco de conversa) teve a emoção da chegada ao ambiente, a apresentação do grupo, motivado pela familiarização com o TelEduc. Tanto a comissão coordenadora, como as tutoras, aprenderam a utilizar as ferramentas do TelEduc, como o "perfil", "mural", "correio", "bate-papo" e sendo assim, identificamos a primeira categoria específica "acoplamento específico com o ambiente TelEduc".

O segundo grupo foi identificado ao percebermos que a apropriação dos espaços do curso gerou uma grande inquietação e angústia para o grupo. Foi um período de intensas trocas de mensagens, pedidos de ajuda à coordenadora e também às colegas. As tutoras tinham muitos problemas com as senhas e logins para acessar os três espaços diferentes. Também apresentavam dificuldades em distinguir a função de cada um deles. Angústias estas que aos poucos foram cessando, à medida que as tutoras foram acoplando-se aos diferentes espaços do curso. Assim emergiu a segunda categoria específica: "acoplamento com os espaços do curso".

O último grupo de mensagens (terceiro) foi identificado pela emoção envolvida nas trocas de mensagens no "correio" após um encontro presencial, ocorrido em Porto Alegre. O grupo, interagindo na linguagem, demonstrou a sua 
união através da aceitação do outro como legítimo outro, com isso, constituindo uma rede de interações que operou como um meio no qual os sujeitos se realizaram como membros de um grupo. Então o "acoplamento entre o grupo", constituiu a terceira categoria específica.

O conjunto de mensagens identificadas através desses três momentos (ou cortes no tempo), - acoplamento com o ambiente TeIEduc, acoplamento com os espaços do curso e acoplamento entre o grupo - nos permitiu acompanhar como os integrantes do espaço coordenação/tutoria, através deste correio, começaram a operar em coordenações consensuais de ações, visto que interagiam recorrentemente na linguagem, como demonstrado pela quantidade de mensagens e pelo período em que foram trocadas. O conjunto dos participantes estava não só coordenando suas ações ao conversar, mas gerando uma rede de interações e com isto produzindo um espaço de ações de aceitação do outro na convivência, em acoplamento com o ambiente, tanto quanto entre si.

Para fins de análise, cada categoria específica foi subdividida em subcategorias. E, foi a partir destas três categorias específicas e das subcategorias que emergiu a categoria geral: acoplamento. Ao nosso ver (e em consonância com a teoria de referência), os três momentos recortados, a partir dos critérios já referidos; intensidade e tempo de duração das conversas; envolvimento emocional dos sujeitos participantes - podem ter constituído momentos intensivos (e extensivos, até certo ponto) dos processos de acoplamento estrutural "organismo-meio" e organismos entre $\mathrm{si}^{\prime}$, visíveis pela análise. Sendo assim, as categorias que orientaram a análise das redes de conversação dos três focos de conversas retiradas do total de mensagens foram:

\section{A) Categoria geral:}

acoplamento

B) Categorias específicas:

b1) Acoplamento com o ambiente TelEduc

b1.1) Acolhimento

b1.2) Perfil

b1.3) Diferença entre mural e correio

b1.4) Bate-papo

b2) Acoplamento com os espaços do curso b2.1) Espaços do curso

b2.2) Dificuldade de acesso

b3) Acoplamento entre o grupo b3.1) União do grupo

Cada um dos três grupos de mensagens (focos de conversas) corresponderá, na análise, a uma categoria específica e possui uma mensagem que foi considerada como sendo a mensagem deflagradora das demais mensagens do grupo, ou seja, a que origina as demais coordenações consensuais de ações. A mensagem deflagradora identificada em cada um dos três grupos, é a mensagem por onde iniciam as demais interações correspondentes ao domínio de ação específico daquele foco de conversa. Já as subcategorias representam a ligação (o acesso) da mensagem à categoria específica e consequentemente à categoria geral.

Na Figura 02 procuramos demonstrar a metodologia de análise realizada.

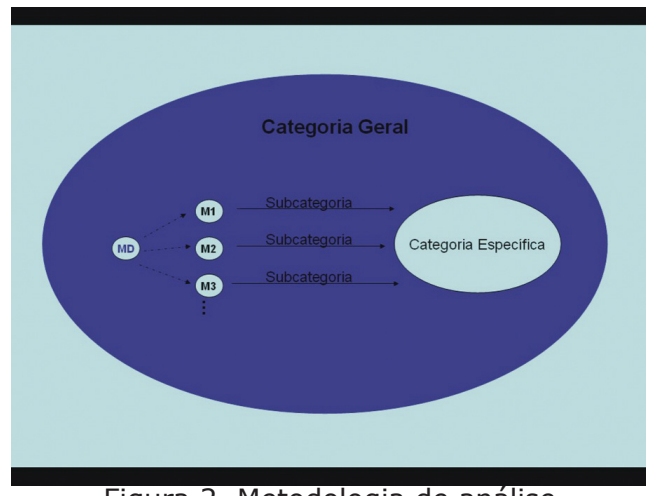

Figura 2. Metodologia de análise 
Podemos, desta forma - Figura 2, identificar a mensagem deflagradora (MD) dando origem às demais mensagens $(M 1, M 2, M 3 \ldots)$ que se conectam à categoria específica e consequentemente à categoria geral, através da(s) subcategoria(s). Cada nova mensagem postada vai se entrelaçando a rede de conversação representada pelo domínio da categoria específica, através da(s) subcategoria(s), exemplificando, assim, coordenação de ações.

\section{Analisando a rede de conversação no correio}

A primeira mensagem foi postada em 20 de abril de 2007 e a última em 11 de abril de $2008^{1}$, sendo que os três focos de análise, da rede de conversação (grupos de mensagens) estão distribuídos ao longo do período, ou seja, as primeiras redes de conversação marcam o início das interações (abril 2007), a segunda, se mostra em meados de junho, e a terceira foi identificada em novembro. Cabe ressaltar que as mensagens selecionadas dizem respeito ao nosso domínio de coerências operacionais e que são constitutivas de viver. Com isso as distinções pertencem às nossas coerências operacionais, como um sistema vivo que vive na linguagem (BEILER, 2004). Nos mapas das redes de conversação, as coordenadoras foram identificadas pela letra " $C$ ", seguida pela letra inicial do nome e as tutoras, pela letra " $T$ ", seguida pelo mesmo critério. Nas mensagens, apenas utilizamos a letra inicial do nome, tanto para as coordenadoras como para as tutoras. $E$ as palavras que identificam as subcategorias foram salientadas em negrito.

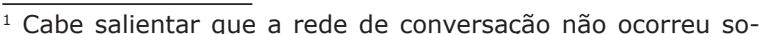
mente através do ambiente virtual. Encontros presenciais, conversas por telefone, videoconferência contribuíram para a constituição da rede de conversação do sistema social.
}

\subsection{Primeiro grupo de mensagens}

O primeiro grupo de mensagem por nós selecionadas referem-se ao "Acoplamento com o ambiente TelEduc (b1) As mensagens aqui selecionadas referem-se à "chegada" das tutoras e da comissão coordenadora ao espaço de coordenação/tutoria, antes do início do curso. Este período foi de capacitação no uso do ambiente TelEduc para, no mês seguinte, assumirem o papel de formadoras.

O acesso ao novo espaço necessitou de um acolhimento e de uma familiarização com os recursos (ferramentas) ali presentes. É por este motivo que identificamos as coordenações consensuais de ações a partir de quatro subcategorias já referidas:

Escolhemos as respectivas subcategorias por elas representarem as ferramentas do TeIEduc que as tutoras mais utilizaram no espaço coordenação/tutoria e, portanto, tiveram a necessidade de aprender a usá-las no papel de alunas para, como tutoras, em seus respectivos grupos, ensinarem seus alunos e as utilizarem com eles.

No exemplo a seguir, destacamos a mensagem de número 01 por considerarmos ser ela a deflagradora das demais coordenações consensuais de ações que fazem parte desta categoria e, por ela, estarem coordenadas num contexto de interações. Isto nos permite ver que esta rede de conversação operou no domínio cognitivo do curso, na medida em que destaca como o processo de acoplamento com o ambiente produz mudanças na estrutura dos sistemas, que, por sua vez, agem sobre ele, alterando-o, numa relação circular, o que Maturana denomina acoplamento estrutural, no caso com o TelEduc. Observa-se que a alteração do ambiente propriamente dita, entendemos que se dê à medida que vai sendo 
povoado de mensagens, transformando-o em ambiente de aprendizagem.

Mensagem no 01 , postada em 20/04/2007 às

22:12

Assunto: boas vindas

Ola!

Sejam bem vindos à nossa sala de aula virtual, onde vamos conviver nas próximas semanas. Sintam-se à vontade para escrever caso surja alguma dúvida. Estou aqui para auxiliá-los nesta caminhada.M.

Nesta mensagem (número 01), uma das coordenadoras está acolhendo o grupo de tutoras e os demais integrantes da comissão coordenadora, oferecendo-se para mostrar o ambiente e estimulando o ato de conversar.

Mensagem no 02 , postada em 22/04/2007 às $14: 24: 13$

Assunto: Resp: boas vindas

Oi M., adorei o teleduc e espero que nossas/os alunas, possam aproveitar tanto quanto eu. J.

Percebe-se que a mensagem número 02 é resposta à número 01 , pois, além de a tutora expor sua boa impressão ao ambiente e dizer que já está aproveitando o novo espaço de convivência, ambas se enquadram na subcategoria acolhimento (b1.1)

E, assim as "discussões" entre o grupo continuaram, estruturando a rede de conversação da categoria "acoplamento com o ambiente TeIEduc", onde as tutoras, aos poucos, num dar voltas com as colegas, demonstram um acoplamento com as ferramentas do Perfil, Mural, Correio e Batepapo e, consequentemente, com o espaço coordenação/tutoria do TelEduc.

A Figura 03, representa as interações referentes ao primeiro grupo de mensagens trocadas entre o grupo no espaço coordenação/tutoria, durante os dez primeiros dias de acesso ao ambiente TelEduc. Este foi o período em que as tutoras trocaram várias mensagens para ingressar no ambiente.

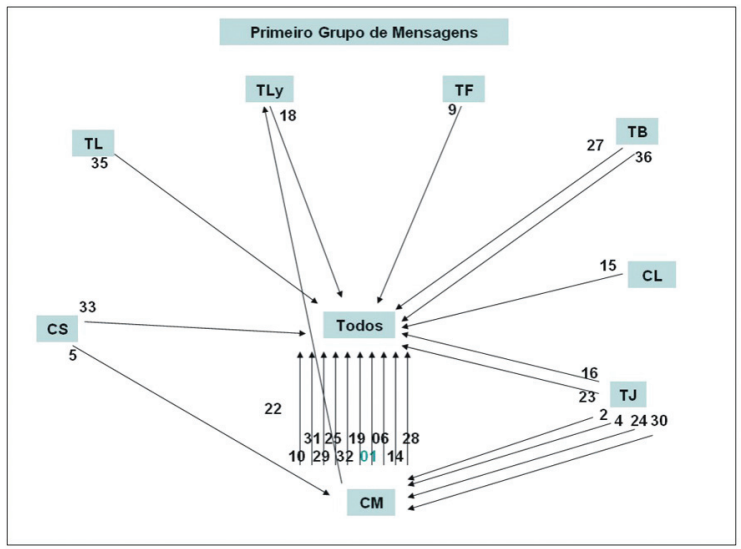

Figura 3. Rede de conversação referente à categoria específica

"acoplamento com o ambiente TelEduc"

Percebe-se, a partir do mapa da Figura 03, que as atividades iniciais estão centradas na professora coordenadora do curso (CM), que acolheu, respondeu e orientou os primeiros passos no ambiente, assim como continuou ocorrendo no período seguinte. O grupo comunica-se entre si através do sujeito "todos". Ao que tudo indica estas mensagens marcam o início de um processo de constituição de um sistema social, "já que proporcionam o compartilhamento do conteúdo das mensagens com o grupo" (CARNEIRO, 2003, p.97). O AVEA, neste período observado, foi utilizado como um espaço de apropriação e convivência com o professor e colegas. A troca de mensagens entre o grupo parece não ser significativa, entretanto, a maior parte das interações foram endereçadas para "todos os formadores", o que demonstra, desde já, a socialização no conteúdo das mensagens. 


\subsection{Segundo grupo de mensagem}

O segundo grupo de mensagens refere-se à categoria específica "acoplamento com os espaços do curso" (b2), que está subdividida nas outras duas subcategorias (b2.1 e b2.2). Estas mensagens datadas no mês de junho de 2007, início do curso, exemplificam uma rede de conversação estabelecida a partir do acoplamento com os espaços do curso.

As tutoras necessitavam acessar três espaços (Três cursos no TelEduc). Um, referente ao espaço onde a pesquisa foi realizada, que é o espaço coordenação/tutoria, outro referente ao seu grupo de orientação (tutoria) e, por último, o espaço do curso de especialização (Figura 1). Devido ao problema enfrentado com as senhas e logins, objetivos distintos, optamos por selecionar as subcategorias b2.1 e b2.2.

As mensagens trocadas entre o grupo neste período mostram, em um primeiro momento, as dificuldades de acesso e apropriação, porém, com o decorrer das interações, identifica-se o acoplamento entre as tutoras e os espaços do curso.

A mensagem número 75 , como podemos perceber, desencadeou as demais coordenações consensuais de ações que fazem parte desta categoria e por ela estão coordenadas num contexto de interações que nos permite afirmar que o grupo que constitui este correio operou em coordenações consensuais de ações, isto é, o grupo interagiu recorrentemente na medida em que se acoplou ao ambiente TelEduc e aos espaços do curso. A tutora pede ajuda aos colegas e à professora para entrar no seu grupo de tutoria, pois não consegue ter acesso ao espaço.
Mensagem no 75, postada em 12/06/2007 às $11: 27: 32$

Assunto: Entrada no ambiente dos alunos Queridos estou com problemas para entrar no grupo dos apoiadores. Ontem foi um pouquinho difícil, mas depois deu certo, fiz meu cadastro e deixei mensagens no correio. Agora não consigo entrar. Coloco login e senha deste espaço, a janela volta a aparecer, pedindo a senha novamente, e não consigo entrar. Alguém deparou-se com este problema? Agora que já vi os grupos formados estou louca para usar e marcar o bate-papo de sexta. Socorro Profa M. bjs, B.

Nesta mensagem (número 75), percebe-se a dificuldade de apropriação com os três espaços, dificuldade com login e senhas, porém é notório o acoplamento que ocorreu com o ambiente TelEduc, expresso na fala da tutora ao dizer que está "louca para usar e marcar o bate-papo com seu grupo de apoiadores".

Cabe ainda salientar que a mesma está coordenada à categoria específica "acoplamento com os espaços do curso" (b2) através da subcategoria "dificuldade de acesso" (b2.2). $E$, assim sucessivamente as mensagem vão se entrelaçando na rede, demonstrando coordenações de ações estabelecidas no acoplamento com os espaços do curso, como podemos observar na mensagem de número 87 .

Mensagem no 87 , postada $13 / 06 / 2007$ às 11:06:45

Assunto: QUE PAGAÇÃO DE MICO, ACHEI !!!!! AMBIENTE DOS ALUNOS

Agora caiu a ficha. Não havia feito o cadastro no ambiente de meu grupo de apoiadoras, usava a senha do ambiente geral do curso. São 3 ambientes. Obrigada T., depois da dica, caiu a ficha. Prof.M. agora está OK. C. acho que a nossa dúvida era a mesma, chegaram duas senhas por correio para os diferentes ambientes. Dá uma olhada. Bjs em todos, B. 
Desta forma a Figura 04 representa as interações referentes ao segundo grupo de mensagens trocadas durante os primeiros dias do início do curso.

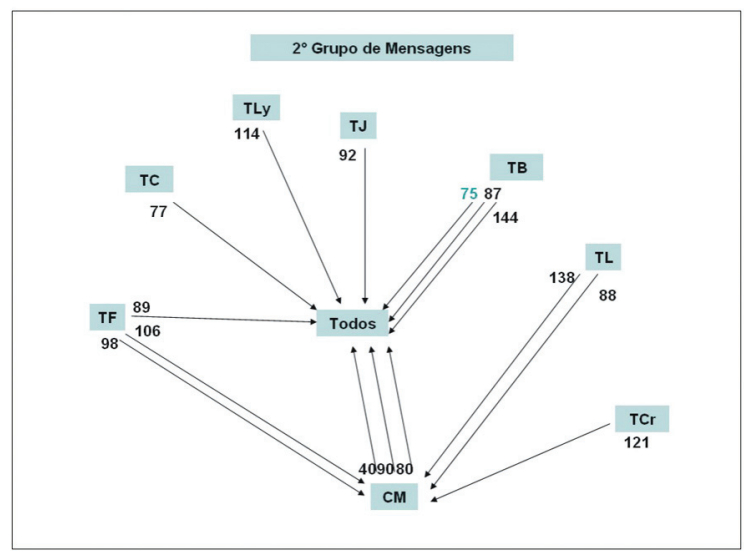

Figura 4. Rede de conversação referente à categoria específica "acoplamento com os espaços do curso"

Novamente o mapa concentra-se na coordenadora (CM), para quem, em um primeiro momento, as tutoras pedem ajuda para entrar nos diferentes espaços, já que estão com dificuldade de acesso. A coordenadora explica os diferentes espaços que o curso contempla, procurando orientá-las. Aqui, embora repita a socialização entre o grupo, identificada pelo compartilhamento das mensagens para "Todos" os formadores, aparecem algumas mensagens trocadas somente entre as tutoras e a coordenadora, o que pode ser resultado de um constrangimento em relação às senhas e logins. Percebe-se também o acoplamento com o ambiente de ensino e aprendizagem, pois o grupo, em sua "fala", acessa tranquilamente todas as ferramentas e sucessivamente os três espaços do curso.

\subsection{Terceiro grupo de mensagem}

Desde o início dos trabalhos, as mensagens por nós selecionadas referem-se a momentos intensivos de emoção dos participantes do espaço coordenação/tutoria que, através de suas interações recorrentes, acabam por compor uma rede de coordenações de ações num domínio de aceitação mútua. No caso do terceiro conjunto de mensagens, foi a partir de um encontro presencial ocorrido no mês de novembro, que os integrantes do grupo vivenciaram uma experiência compartilhada sob a emoção da amizade e do companheirismo. Sendo assim, procuramos identificar as coordenações consensuais de ações a partir da subcategoria "união do grupo". Esta escolha foi feita tendo como base as idéias de Humberto Maturana e Francisco Varela, quando dizem que "cada indivíduo está continuamente ajustando sua posição na rede de interações formadas pelo grupo, segundo sua dinâmica particular, que resulta de sua história de acoplamento estrutural grupal" (MATURANA, 2001, p. 213).

Optamos por relatar as mensagens trocadas pelo grupo após um encontro presencial, pelo fato de o curso estar estruturado a partir de encontros a distância, pelo ambiente, além dos encontros presenciais. As duas mensagens a seguir relatam a emoção vivida pelo grupo a partir de um encontro descentralizado. Pelo fato de tomarmos a categoria específica b3 (acoplamento entre o grupo) como apenas uma subcategoria (b3.1), todas as mensagens aqui selecionadas estão coordenadas à rede através da mesma subcategoria: união do grupo.

A mensagem número 443 foi identificada como sendo a "fala" deflagradora desta seqüência de relatos sobre o encontro presen- 
cial vivenciado pelo grupo no mês de novembro. Nela a tutora reflete sobre as vivências humanizadoras que o curso tem proporcionado e acrescenta que nunca se sentiu tão bem acompanhada e feliz pela oportunidade de estar compartilhando momentos especiais como o do encontro. Esta última frase, vinculada às demais mensagens selecionadas neste grupo, nos ajuda a pensar na confirmação de parte da hipótese, em que uma rede de coordenações de ações confirma a constituição de um sistema social.

Mensagem no 443, postada em 12/11/2007 às $21: 51$

Assunto:Ultimo encontro presencial

Talvez tenhamos vivido neste final de semana um momento definitivo nas nossas vivencias humanizadoras. Principalmente nós tutoras, inventoras desta nova trilha (e Cr., T. e L. as reais desbravadoras) tenhamos sentido alguns arranhões, picadas de insetos, sensações de estarmos perdidas, mas ao mesmo tempo encantadas com cada paisagem nova que se apresentava. Quero dizer a todas vocês que nunca me senti tão bem acompanhada e feliz por estar tendo a oportunidade de viver tudo isto quando muito dos colegas não conseguem mais ter tesão de encarar novas aventuras.

Encontrei um texto que sinto tem tudo a ver e quero compartilhar com vocês. Não sei $\mathrm{Cr}$. qual é o nosso conceito, mas tenho certeza que nossos desejos e sonhos são muito valiosos. Um grande beijo! Ly.

Arquivos anexos:PESQUISADOR E EXPERIMENTADOR.doc

Através desta mensagem (número 443), a tutora compartilha um texto "Pesquisador e Experimentador" com as colegas. O autor deste texto nos fala que não existe um método científico único, devemos ir experimentando a melhor forma de pesquisar, conforme nossos objetivos e maneiras de ser seres humanos. 0 que também merece a nossa atenção é o ato da socialização, que

decorre da recorrência de interações que resultam num viver juntos em uma deriva estrutural co-ontogênica, e a linguagem é uma maneira de viver juntos. A recorrência de interações na espontaneidade do prazer, sem justificativas, é o fenômeno da socialização (MATURANA, 2002, p. 183).

Socializar, segundo o dicionário Houaiss (2001), significa tornar social, compartir. Só compartilhamos quando há um sentimento de amor envolvido nas relações.

O amor é a fonte da socialização humana, e não o resultado dela, e qualquer coisa que destrói o amor, qualquer coisa que destrói a congruência estrutural que ele implica, destrói a socialização. A socialização é o resultado do operar no amor, e ocorre somente no domínio em que o amor ocorre (MATURANA, 2002, p. 185).

Então, quando a tutora compartilha o texto com as colegas, e através da linguagem, vivem juntas as idéias do autor no domínio cognitivo do curso, estabelecendo elos entre a sua própria fala com dados e experiências vividas no curso e fora dele, podemos dizer que o grupo está operando num sistema linguajante.

Mensagem no 444, postada em 13/11/2007 às $07: 13: 53$

Assunto: Resp: Ultimo encontro presencial Feliz daquele que como nós pode passar por experiências ricas como estas, crescer com elas e, principalmente, saber que sempre em qualquer momento teremos umas as outras. O texto é maravilhoso. Beijos em todas. B.

A colega responde, através da mensagem número 444 , dizendo que o texto realmente é 
muito bom e o principal é saber que o grupo está unido para qualquer situação. Então, se viver implica conhecer, seguir vivendo implica aprender. Dito de outra forma: vivendo e aprendendo, aprendendo e vivendo. A Figura 05 representa as interações referentes ao terceiro grupo de mensagens trocadas durante 0 mês de novembro.

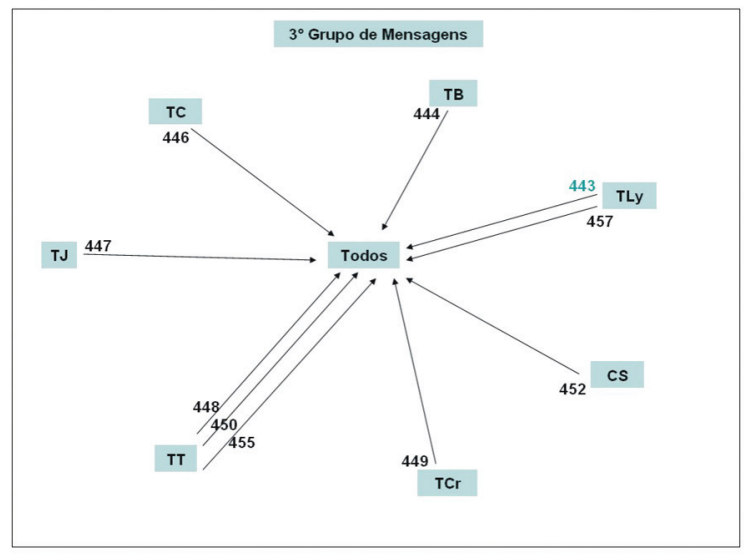

Figura 5. Rede de conversação referente à categoria específica "acoplamento entre o grupo"

O mapa da figura 05 já não está mais centrado na coordenadora e sim na constituição do sistema social, através do sujeito coletivo "Todos", que, nestas mensagens trocadas, segue um curso operacional de aceitação mútua. Percebemos também que seis das oito tutoras interagem na conversa, o que demonstra a união de um grupo que, através da emoção, compartilha na rede a alegria de estar unido.

Desta mesma forma e contexto, outras mensagens são postadas no correio do espaço coordenação/tutoria, como por exemplo a de número 646, que, embora não esteja mais no domínio de ação do "último encontro presencial", nos faz pensar na co-existência de outras redes de conversação que identificam a união do grupo. Sendo assim, em outros períodos e situações as mensagens representadas atra- vés da subcategoria b3.1, podem nos ajudar a pensar na confirmação da constituição de um sistema social.

Mensagem no 646, postada em 10/03/2008 às $07: 58: 49$

Assunto: sinto falta de trocas com outras tutoras

Gente o que é este silêncio no espaço coordenação/tutoria? Socorroo00000000000! Eu não agüento! Sinto falta de troca.... preciso para sobreviver... Tutora L.

As mensagens apresentadas nos indicam a existência de redes conversacionais definidas por Maturana e Varela (2001) como acoplamentos estruturais de terceira ordem, consequência das interações recorrentes entre organismos que ocorrem de forma que permitam a manutenção da individualidade de ambos, no prolongado devir de suas interações. Sempre que o acoplamento ocorre, gera uma fenomenologia interna específica.

Essa fenomenologia se baseia no fato de que os organismos particulares satisfazem suas ontogenias individuais principalmente por meio de seus acoplamentos mútuos, na rede de interações recíprocas que formam ao constituir as unidades de terceira ordem. Os mecanismos mediante os quais essa rede e as unidades que a constituem se estabelecem variam de caso para caso, mas mantém sua coesão (MATURANA; VARELA, 2001, p.214).

\section{Analisando o questionário aplica- do as tutoras}

Para validar nossas análises, fizemos alguns questionamentos às tutoras e ao perguntarmos sobre o acoplamento com o ambiente, pudemos perceber que duas (29\%) das sete tuto- 
ras que responderam ao instrumento, tiveram receios e dificuldades de usar as ferramentas, o que, segundo seus relatos, gerou angústia e insegurança inicial, melhorando no decorrer do curso. A maioria das tutoras (04) relatou ter gostado da possibilidade que as ferramentas oferecem, como por exemplo, o acompanhamento mais próximo do desempenho de cada aluno no espaço de tutoria, acrescentando ser o correio a ferramenta que tiveram mais facilidade para acessar. As três (03) restantes não destacaram nenhuma das ferramentas por acharem todas de simples acesso. Uma das tutoras relatou que o problema foi o acesso aos diferentes espaços de atuação no TelEduc.

Da mesma forma foi questionado sobre a ferramenta que tiveram menos facilidade para acessar, e três (03) das sete tutoras responderam que foi o diário de bordo. Uma sentiu dificuldade no bate-papo, relatando:

...Acredito ser o bate-papo, pois descobri que se ficava um tempo sem digitar e o sistema me excluía. Também, por vezes, digitava rápido e as palavras não apareciam simultaneamente ao momento da digitação, E, por último, sempre esqueço de trocar o interlocutor quando quero dirigir-me apenas a um colega. Considero estas questões mais de ordem de adequação ao ambiente do que propriamente de dificuldades (TB, 28/01/2208).

Outra tutora relatou ter tido dificuldades com a "agenda", e as duas restantes não tiveram dificuldades com nenhuma ferramenta específica. Esta dificuldade deve-se ao fato de que, durante o curso, foi solicitado pela comissão coordenadora que as tutoras publicassem suas próprias agendas nos seus espaços de tutoria. Porém, todas as tutoras questionadas relataram ter utilizado o correio como a ferramenta mais acessada. O ambiente, como percebido, também sofreu transformações na medida em que foi modificado pelo grupo para melhor adaptar-se a ele, buscando atender suas necessidades. Estas modificações são identificadas na escolha das ferramentas, nos materiais disponíveis no ambiente e na própria estrutura das redes de conversação.

As tutoras ao responderem os aspectos positivos de trabalhar através de um ambiente virtual de aprendizagem, expressaram em seus relatos ter sido a possibilidade de trocar experiências com pessoas distantes geograficamente, permitindo a frequente socialização. "A possibilidade de aquecer as relações e manter as trocas de uma forma regular e sistemática" (TF). Uma das tutoras relatou ser a "possibilidade de formação de redes de conversa".

Sendo assim, o acoplamento estrutural consistiu na correspondência espaço-temporal efetiva entre as mudanças dos comportamentos do grupo e as mudanças recorrentes de estado do ambiente, enquanto o grupo permaneceu em autopoiese (MATURANA, 2001).

"Quando, num organismo, existe um sistema nervoso tão rico e tão vasto como o do homem, seus domínios de interações permitem a geração de novos fenômenos" (MATURANA, 2001, p. 196). Assim como nas comunidades, é necessário, no ciberespaço, o acoplamento tecnológico entre professores, alunos e ambientes de aprendizagem (AXT; MARASCHIN, 2005). Neste acoplamento tecnológico, as mudanças não se deram a partir da lógica da tecnologia; essa, por sua vez, desencadeou perturbações, mas o curso daquelas foi guiado pela estrutura dos atores envolvidos (coordenação, tutoras e monitoras), inseridos na lógica do sistema (BEILER, 2004).

O meio desencadeia mudanças de estado no sistema, e o sistema desencadeia mudanças de estado no meio. Que mudanças de estado? Uma mudança permitida pela estrutura 
do sistema. [...] O meio seleciona a mudança estrutural no organismo, e o organismo, através da sua ação, seleciona a mudança estrutural no meio (MATURANA, 2002, p. 61).

O que nos faz pensar que o ambiente TelEduc, através da sua estrutura e configuração, possibilitou mudanças estruturais no grupo. $\mathrm{E}$ o grupo, através de sua ação, selecionou as mudanças no ambiente.

\section{Algumas reflexões}

O que vemos como comportamento em qualquer ser vivo sob a forma de ações em um contexto determinado é, digamos assim, a coreografia de sua dança estrutural. Como resultado disso, a conduta de um ser vivo é adequada somente se suas mudanças estruturais ocorrerem em congruência com as mudanças estruturais do meio (MATURANA, 2002, p. 196).

Analisando o meio, as ações, as mensagens selecionadas, em que procuramos mostrar os acoplamentos possíveis, percebemos, através das redes de conversação que "nós, seres humanos, acontecemos na linguagem, e acontecemos na linguagem enquanto o tipo de sistemas vivos que somos" - Sistemas determinados pela nossa estrutura (MATURANA, 2002, p. 269). Isto é de tal modo que o viver é um fluir ininterrupto de mudanças estruturais, e estas mudanças se dão sempre de maneira contingente com nossas interações no meio. Nossa estrutura está sempre estruturalmente adaptada ao meio (MATURANA, 2001b).

Seguindo estas ideias, podemos dizer que a estrutura do sistema estabelece uma correspondência mútua e dinâmica com o meio, determinando no sistema um domínio de estados e um domínio de perturbações que lhe permi- te operar recorrentemente em seu meio, sem desintegração, através do acoplamento estrutural (CARNEIRO, 2003). Em outras palavras, podemos observar, a partir das ideias de Maturana e Varela (2001), que o sistema vivo e o meio em que ele vive se modificam de forma congruente. Tomemos como exemplo o grupo estudado que esteve sempre no processo de acoplamento com o ambiente TelEduc e os espaços do curso. Desta forma, estamos dizendo que o meio produziu mudanças na estrutura dos sistemas, que por sua vez agiu sobre ele. O acoplamento estrutural é sempre mútuo: no caso, o grupo e o ambiente sofreram transformações, o primeiro, na medida em que realizou aprendizagens sociais e cooperativas, constituindo-se como grupo (sistema social) e construindo conhecimento; já o segundo se formou num ambiente de aprendizagem à medida que suportou os processos de interação por ele mediados.

As transformações sofridas pelo grupo puderam ser identificadas através das redes de conversação em que podemos observar o acoplamento que ocorreu com o ambiente TelEduc, a familiarização com as ferramentas, bem como com os três diferentes espaços.

Assim, partir da análise das 708 mensagens do correio no ambiente TelEduc no espaço coordenação/tutoria, identificamos estes três grupos de mensagens apresentadas, pois nosso objetivo principal é mostrar um de muitos processos de constituição de um sistema social em um ambiente virtual de ensino e aprendizagem, no caso o Curso de Especialização em Atenção e Gestão do SUS, naquilo que diz respeito aos integrantes do espaço coordenação/ tutoria.

Como observadores desta comunidade, pudemos estudar um modo como o processo de relação teve início e foi se constituindo. Assim, 
nas três situações estudadas pôde-se identificar a existência de redes de conversações constituídas mediante processos de acoplamento. Consideremos como, a partir dos acoplamentos, pôde-se observar a constituição de um sistema social.

Um grupo formado por oito profissionais da área da saúde, juntamente com uma comissão coordenadora e com monitoras, a partir de um determinado momento, começou a conviver nos espaços que o curso contemplava. No chamado espaço "coordenação/tutoria", o grupo se acoplou ao meio (TelEduc), aprendendo a utilizar todas as ferramentas disponíveis, num acoplamento estrutural entre o sistema vivo e o meio. Ao dar voltas umas com as outras, no entrelaçar do linguajar e do emocionar, as tutoras transformaram suas próprias ações, dando origem a novas configurações de ações coordenadas que confirmou a identidade deste sistema como um sistema social da $\mathrm{PNH}$, ocorrendo, assim, um acoplamento estrutural entre os indivíduos do grupo (ROCHA, 2008). Podemos identificar este acoplamento entre o grupo através das mensagens por nós selecionadas que demonstraram o prazer da companhia ao viverem juntas um curso na área da saúde.

Também pudemos observar o acoplamento entre o grupo a partir de depoimentos avaliativos no final do curso (terceira interação analisada); e, também na medida em que questionamos as tutoras como elas enxergaram o estabelecimento das relações entre o grupo, mediado pelo ambiente virtual.

Nós, seres humanos, não somos indivíduos senão no contexto de sistemas sociais onde nos integramos, e sem seres humanos individuais não haveria fenômenos sociais humanos (MATURANA, 2002). Da mesma forma um sistema social humano é definido como tal pela aceitação mútua de seus componentes em sua condição de seres humanos, ou seja, o sistema social da PNH é definido como tal pela aceitação mútua de seus componentes na condição de participantes do curso de especialização.

Em outras palavras, os componentes deste sistema social conservaram sua adaptação recíproca no domínio de aceitação mútua, enquanto se realizaram a si mesmos como sistemas vivos em suas derivas estruturais co-ontogênicas, através de suas coordenações recorrentes de ações. Em sistemas sociais humanos como este, isso ocorre através do linguajar (MATURANA, 2002) e, em consequência disso, é que a mudança estrutural se dá, tanto como resultado de sua dinâmica interna, como desencadeada por suas interações em um meio que também está em contínua mudança.

Além disso, pudemos observar, através das redes de conversação apresentadas, que este sistema social humano constituiu redes de conversações recorrentes e cambiantes entre os seres humanos que permitiu a realização de seus indivíduos enquanto seres humanos na participação da constituição do sistema social que eles integraram (Ibid.).

Nós, seres humanos, existimos em comunidades constituídas como sistemas de coordenações de ações na linguagem sob certas emoções, ou seja, constituídas como redes de conversações. Se a emoção é o amor, ou seja, se a emoção envolvida é a emoção que contribui a operacionalidade de interações recorrentes sob a aceitação mútua, então a comunidade é um sistema social (MATURANA, 2002, p. 308-309).

Um sistema constituído por sistemas vivos que, através de suas interações recorrentes, integram uma rede de coordenações de ações num domínio de aceitação mútua, é um sistema social naquele domínio (MATURANA, 2002, p. 301). 
A construção dos mapas de interação, a partir das mensagens trocadas entre os participantes (coordenadores, tutores, monitores) mostra, ao longo dos períodos analisados, os nós da rede que ora se centram na coordenadora, ora se alternam entre os participantes. Observamos também a constituição de um sujeito coletivo ("nós" - formado pelos participantes do curso), representado nos mapas pelo símbolo "Todos" (ROCHA, 2008).

Sofremos mudanças estruturais contínuas ao mesmo tempo em que conservamos o padrão de organização em redes de conversação. Nestas redes os componentes produzem e se transformam uns aos outros, ligando-se estruturalmente ao meio, através das interações recorrentes, onde cada uma das interações desencadeia mudanças estruturais no sistema.

Os conceitos centrais da teoria da Biologia do Conhecer, cunhados por Humberto Maturana e norteadores desta investigação, nos apresentaram uma outra definição de comunidade, um conceito que fala das emoções que tornam possíveis as interações recorrentes sob a aceitação mútua em sistemas de coordenações de ações na linguagem. Sendo assim, "a comunidade é um sistema social" (MATURANA, 2002, p. 309).

\section{Referências}

AXT, Margarete. Comunidades Virtuais de Aprendizagem. Informática na educação: teoria \& prática, Tecnologia Digital na Educação, Porto Alegre, v. 7, n. 1, p. 111-116, jan./jun. 2004.

AXT, Margarete; MARASCHIN, Cleci. Acoplamento Tecnológico e Cognição. In: VIGNERON, Jacques; OLIVEIRA, Vera Barros de (Org). Sala de aula e Tecnologias. São Bernardo do Campo: Universidade Metodista de São Paulo, 2005, p. 39-51.

BEILER, Adriana. A produção de redes de conversação como base à aprendizagem. Porto Alegre: UFRGS, 2004. Tese (Doutorado em Informática na Educação), Centro Interdisciplinar de Novas Tecnologias na Educação, 2004.

CARNEIRO, Mara. O acoplamento tecnológico e a comunicação em rede: inventando outros domínios de aprendizagem. Porto Alegre: UFRGS, 2003. Tese (Doutorado em Informática na Educação), Centro Interdisciplinar de Novas Tecnologias na Educação, 2003. 
HOUAISS, Antônio; VILLAR, Mauro de Salles. Dicionário Houaiss da Língua Portuguesa. Instituto Antônio Houaiss de Lexicografia e Banco de Dados da Língua Portuguesa. Rio de Janeiro: Objetiva, 2001.

MARIOTTI, Humberto. Prefácio. In: MATURANA, Humberto; VARELA, Francisco. Árvore do Conhecimento: as bases biológicas da compreensão humana. São Paulo: Palas Athenas, 2001.

MATURANA, Humberto; VARELA, Francisco. A árvore do conhecimento: as bases biológicas da compreensão humana. São Paulo: Palas Athena, 2001.

Cognição, ciência e vida cotidiana. Belo Horizonte: Editora UFMG, 2001b.

MATURANA, Humberto. A ontologia da realidade. Belo Horizonte: Ed. UFMG, 2002.

PALLOFF, Rena; PRATT, Keith. Construindo comunidades de aprendizagem no ciberespaço: estratégias eficientes para salas de aula on-line. Traduzido por Vinícius Figueira. Porto Alegre: Artmed, 2002.

ROCHA, Karla M. Estudo sobre a constituição de um sistema social em ambiente virtual de aprendizagem. Porto Alegre: UFRGS, 2003. Tese (Doutorado em Informática na Educação), Centro Interdisciplinar de Novas Tecnologias na Educação, 2008.

Submetido para avaliação em 11 de julho de 2013.

Aprovado para publicação em 16 de março de 2014.

Karla Marques da Rocha: Professora Adjunta da Universidade Federal de Santa Maria - Santa Maria - RS - Brasil. E-mail: karlarocha@terra.com.br

Margarete Axt: Professora titular da Universidade Federal do Rio Grande do Sul - Porto Alegre - RS - Brasil. E-mail: maaxt2002@yahoo.com.br 